\title{
PENGARUH KOMPETENSI ENTREPRENEUR, PENGGUNAAN TEKNOLOGI INFORMASI, INOVASI TERHADAP KEUNGGULAN BERSAING MENUJU ASEAN ECONOMIC COMMUNITY 2015
}

(Survei Pada Industri Tenun Sutra di Provinsi Selawesi Selatan dan

Sulawesi Barat)

Oleh :

Dahlia, Meidylisa Patty, Dian Utami Sutiksno

(Magister Ilmu Ekonomi Universitas Padjadjaran Konsentrasi Akuntansi)

\begin{abstract}
Purpose - The purpose of this research is to determine the The effect of entrepreneur competency, the use of information technology, innovation to competitive advantage towards Asean Economic Community 2015(Evidence From Silk Weaving Industry of South Sulawesi \& West Sulawesi Province).

Design/methodology/approach - The research is explanatory research. The research was conducted at the Silk Center Wajo South Sulawesi province and Polman also dubbed as the City of Silk. Data collection technique is distributing questionnaires for 100 Silk Industry, interviews and documentation. The instrument was tested by Spearman and Cronbach Alpha reliability and the classical assumptions. The analytical method used are Multiple Regression Analysis.

Findings - The results of this research showed that the entrepreneur competence, the use of information technology, and innovation have a positive effect to to competitive advantage either partially and simultaneously. Silk also known as "Lipa Sabbe". Silk have mix utility with the local culture aesthetic value.

Originality/value - Although some previous studies conducted related to the competitive advantage but the difference with this research is focused discussion in this research specifically on the Silk Industry/SMEs and have a economic and cultural values are very high. In addition, this research try to combine several variables which still still pose constraint for entrepreneur such as . entrepreneur competency, the use of information technology, innovation.
\end{abstract}

Keywords: Competence entrepreneur, Information Technology, Innovation, Silk

\section{PENDAHULUAN}

Usaha Kecil Menengah (UKM) mempunyai peranan yang penting dalam pertumbuhan ekonomi dan industri dalam suatu Negara (Husband and Purnendu, 1999; Dianne H.B. Welsh, 2013; Roghaye Tavosi Simkani, 2013). Hampir 90\% dari total usaha yang ada di dunia merupakan kontribusi dari UKM Disamping itu, UKM mempunyai kontribusi terhadap penyerapan tenaga kerja. Namun untuk menghadapi krisis ekonomi global dan perdagangan bebas multilateral (WTO), regional (AFTA), kerjasama informal APEC, dan ASEAN Economic Community (AEC) pada tahun 2015, UKM dituntut untuk melakukan pembenahan guna meningkatkan daya saingnya agar dapat terus berjalan dan berkembang. 
Diantaranya dengan cara menggunakan teknologi informasi (TI), Penggunaan teknologi informasi dapat meningkatkan transformasi bisnis melalui kecepatan, ketepatan dan efisiensi pertukaran informasi dalam jumlah yang besar. Studi kasus di Eropa juga menunjukkan bahwa lebih dari 50\% produktifitas dicapai melalui investasi di bidang teknologi informasi. UKM dikatakan memiliki daya saing global apabila mampu menjalankan operasi bisnisnya secara reliable, seimbang, dan berstandar tinggi. Fenomena yang terjadi terlihat bahwa penggunaan teknologi informasi berbasis komputer masih terbatas, contoh masih sedikitnya UKM yang menggunakan aplikasi khusus untuk usaha, menggunakan fasilitas internet, memiliki website, memanfaatkan $e$ commerce dan atau e-business dan lain-lain.

Selain perlunya peran teknologi informasi, peran sumber daya manusia (kompetensi entrepreneur) juga sangat dibutuhkan. Karena SDM bukan hanya dianggap sebagai beban melainkan dianggap sebagai asset yang akan sangat menentukan lancarnya kegiatan organisasi (Francisco Gerardo Barroso Tanoira, 2014; Noor Hazlina Ahmad 2011). Mengembangkan kompetensi yang relevan dalam pengelolaan pengusaha dianggap sebuah langkah penting dalam menyediakan UKM dengan keunggulan kompetitif yang berkelanjutan, terutama karena bisnis semacam ini sangat tergantung pada kemampuan pemilik (Gibb, 2005; Theresa Lau, 2008; Noor Hazlina Ahmad 2011). Dalam studi yang dilakukan di UKM Mexico memperlihatkan bahwa $75 \%$ menegaskan adanya keterkaitan antara kompetensi sumber daya manausia dengan kinerja perusahaan. Sedangkan dalam studi yang dilakukan di Australia dan Malaysia menunjukkan bahwa tingkat kegagalan dari usaha kecil dalam lima tahun pertama mereka adalah lebih dari 50 $\%$, Khususnya di Australia, tingkat kegagalan $23 \%$ telah dilaporkan sedangkan di Malaysia, meskipun belum ada angka yang akurat diterbitkan sejauh ini, tingkat kegagalan diperkirakan untuk UKM adalah 60 \% (Portal KF KTAK, 2006).

Selain dibutuhkannya peran teknologi informasi dan kompetensi dari entrepreneur sebagai pelaku usaha, peningkatan daya saing produk merupakan syarat mutlak yang harus dipenuhi agar dapat bersaing dengan pesaing lainnya. Inovasi berkesinambungan merupakan strategi peningkatan daya saing produk UKM yang memiliki ciri unik dan keunggulan produk. Inovasi juga dipandang sebagai mekanisme perusahaan dalam beradaptasi dengan lingkungannya yang dinamis perubahan perubahan yang terjadi dalam lingkungan bisnis telah memaksa perusahaan untuk mampu menciptakan pemikiran - pemikiran baru, gagasan baru, proses yang baru dan menawarakan produk inovatif. Dengan demikian inovasi semakin memiliki arti penting bukan saja sebagai suatu alat untuk mempertahankan kelangsungan hidup perusahaan melainkan juga untuk unggul dalam persaingan. Hal ini juga sesuai dengan penelitian dari pengaruh inovasi terhadap kinerja dan daya saing telah menjadi subjek analisis, dengan sejumlah studi empiris memberikan bukti efek positif, (Damanpour \& Evan, 1984; Schulz \& Jobe, 2001; Jong \& Vermeulen, 2006; Evelyn Garcia-Zamora 2013). Hasil inovasi, pada kenyataannya, memberikan keunggulan kompetitif yang memungkinkan perusahaan untuk memperoleh keuntungan pada inovasi, seperti penjualan yang lebih tinggi dan pertumbuhan perusahaan. Berbeda dengan penelitian sebelumnya hasil penelitian Barbara (2013) menemukan bukti bahwa penerapan inovasi produk dan atau proses baru dapat meningkatkan daya saing dan profitabilitas secara keseluruhan, jika didasarkan pada kebutuhan pelanggan dan persyaratan, sehingga perhatian harus menekankan perhatian pada permintaan pelanggan. Hasil menunjukkan bahwa adopsi inovasi teknologi UKM untuk mengembangkan inovasi tidak berdampak pada kinerja keuangan dan keunggulan bersaing. 
Sulawesi Selatan dan Sulawesi Barat melalui Kab Wajo dan Polewali Mandar merupakan salah satu sentra - sentra industri dengan produk unggulannya berupa kain sutra. Penelitian ini akan mencoba meneliti bagaimana pengaruh kompetensi entrepreneur, teknologi informasi dan inovasi terhadap keunggulan bersaing menuju Asean Economis Community 2015.

\section{KAJIAN PUSTAKA Kompetensi Entrepreneur}

Kompetensi sumber daya manusia sebagai intangible asset sebuah perusahaan mempunyai kemungkinan untuk menciptakan keunggulan kompetitif (Seeley \& Dietrich, 2000; Francisco Gerardo Barroso Tanoira, 2014), dan itulah sebabnya fokus pada manajemen pengetahuan menganggap manusia sebagai aset terpenting dalam perusahaan. Kompetensi entrepreneur adalah sumber daya yang paling penting dan belajar adalah aset yang paling penting bagi seseorang dalam suatu organisasi .

Kompetensi Entrepreneur mengacu pada kemampuan individu untuk bertindak telah dalam situasi yang berbeda. Kompetensi Entrepreneur merupakan aset yang sangat penting karena tanpa adanya orang-orang tersebut, perusahaan tidak akan ada. Kompetensi ini tergantung dari beberapa faktor diantaranya: (1) pengetahuan eksplisit atau pendidikan formal, (2) Pelatihan/praktek, mengetahui bagaimana melakukan sesuatu yang memerlukan pelatihan dan praktek, (3) Pengalaman dan nilai-nilai, pengetahuan yang diperoleh pada praktek kerja (Francisco Gerardo Barroso Tanoira, 2014; Robbins and Judge, 2013)

\section{Penggunaan Teknologi Informasi}

Teknologi Informasi adalah suatu teknologi yang digunakan untuk mengolah data, termasuk memproses, mendapatkan, menyusun, menyimpan, memanipulasi data dalam berbagai cara untuk menghasilkan informasi yang berkualitas, yaitu inforrnasi yang relevan, akurat dan tepat waktu, yang digunakan untuk keperluan pribadi, bisnis, dan pemerintahan dan merupakan informasi yang strategis untuk pengambilan keputusan. Teknologi ini menggunakan seperangkat komputer untuk mengolah data, sistem jaringan untuk menghubungkan satu komputer dengan komputer yang lainnya sesuai dengan kebutuhan, dan teknologi digunakan agar data dapat disebar dan diakses secara global.

Beberapa penelitian terdahulu terkait mengenai pentingnya teknologi informasi ini seperti penelitian Fathen Jabeur \& Egide Karuranga (2013) menyatakan bahwa Lingkungan bisnis sekarang ini menuntut dan telah memaksa perusahaan untuk menggunakan teknologi informasi (TI) untuk tetap kompetitif. Kemampuan E-bisnis saat ini adalah salah satu faktor yang paling penting yang menawarkan keunggulan kompetitif bagi kebanyakan perusahaan. Dalam penelitiannya diketahui evolusi dari penerapan praktik e-bisnis antara 2002 dan 2009 dari persepsi terhadap adopsi yang sebenarnya oleh UKM Quebec, Kanada. Hasilnya menunjukkan bahwa rendahnya tingkat adopsi teknologi tersebut dalam kelompok ini. Perusahaan yang berskala besar dan bertempat didaerah metropolitan mengadopsi solusi e-bisnis lebih cepat dan dalam volume yang lebih tinggi daripada perusahaan dilakukan di daerah pedesaan.

\section{Inovasi}

Penelitian Droge dan Vickery (1994) menemukan bahwa produk dapat dijadikan sebagai salah satu sumber keunggulan bersaing. Perusahaan yang mampu mendesain produknya sesuai dengan keinginan pelanggan akan mampu bertahan di tengah persaingan karena produknya yang tetap diminati oleh pelanggan. Serupa dengan hal tersebut hasil penelitian Bharadwaj et all (1993) yang mengemukakan bahwa 
kemampuan perusahaan untuk terus melakukan inovasi terhadap produk-produknya akan menjaga produk tersebut tetap sesuai dengan keinginan dan kebutuhan pelanggan. Dengan demikian, inovasi produk dapat dijadikan sebagai sumber dari keunggulan bersaing perusahaan.

Dimensi inovasi dalam penelitian ini mengacu pada kombinasi tentang inovasi yang dilakukan suatu perusahaan waktu ke waktu yang terdiri atas inovasi produk termasuk didalamnya penciptaan produk baru, perubahan desain maupun perubahan komponen dan mutu, dan inovasi proses termasuk pula diantaranya metode produksi baru, pelayanan baru atau gagasan baru dll, (Zahra dan Das,1993; Luisa Carvalho; 2013). Ada beberapa cara yang dapat ditempuh untuk menghasilkan produk yang inovatif diantaranya : Mengembangkan atribut produk baru, Mengembangkan beragam tingkat mutu. Mengembangkan model dan ukuran produk.

Hasil penelitian Jos M. Monteiro Barata (2012:1) peran desain produk dalam perusahaan, akan dianggap sebagai cara yang tepat untuk menganalisis daya saing dalam UKM di Portugis, fungsi desain di samping sebagai inisiatif baru di bidang pemasaran dan inovasi, juga berfungsi dalam produksi dan manajemen operasi yang digunakan tidak hanya sebagai alat optimasi biaya, tetapi juga sebagai driver spesifik dalam menciptakan diferensiasi sehingga dicapai suatu keunggulan. Hasil penelitian Yongyoon Suh \& Moon Soo Kim (2014:1) menyatakan bahwa beberapa hal yang mempengaruhi keberhasilan dalam kinerja UKM yang diidentifikasi dalam perspektif inovasi teknologi (R\&D) dan pemasaran internasional (kepuasan pelanggan). Hasil ini memberikan implikasi penting bagi para pembuat kebijakan yang tertarik pada daya saing UKM internasional secara berkelanjutan.

\section{Keunggulan Bersaing (Competitive Advantage)}

Dalam lingkungan bisnis yang sangat kompetitif, perusahaan harus memiliki kemampuan untuk membedakan produk yang dihasilkan dalam persaingan untuk mendapatkan keunggulan bersaing. Produk yang dihasilkan harus memiliki karakteristik kunci dalam merebut konsumen sehingga menjadi produk yang spesial.

Competitive advantage atau keunggulan bersaing adalah kelebihan yang dimiliki oleh suatu perusahaan dan tidak dimiliki pesaingnya yang menjadikan perusahaan tersebut lebih unggul dibanding para pesaingnya. Beberapa strategi dapat dijalankan perusahaan untuk dapat meraih keunggulan berkompetisi. Perusahaan dapat meraih competitive advantage melalui dua cara yaitu:

1. By lower cost, yaitu kemampuan perusahaan untuk mendesain, memproduksi dan memasarkan produk dengan lebih efisien dibandingkan pesaingnya.

2. By differentiation, yaitu kemampuan perusahaan untuk menghasilkan nilai lebih (superior value) kepada konsumen dengan meningkatkan kualitas produk, memberikan produk yang unik atau spesial serta pelayanan jasa yang lebih baik dibanding pesaingnya. (Porter, 1980; Hansen Mowen, 2009; Hunger, 2013; Craven 2012)

Strategi diatas dimungkinkan dapat dicapai dengan bantuan teknologi informasi, senantiasa melakukan inovasi yang diaplikasikan oleh suatu organisasi. Apabila organisasi pada tahapan selanjutnya telah memiliki keunggulan berkompetisi, maka akan diikuti dengan peningkatan business-value, demikian juga costumer-value.

\section{III.METODOLOGI}

\section{Sampel dan Data Penelitian}

Penelitian ini dilakukan untuk memperoleh data-data yang memberikan gambaran tentang pengaruh kompetensi entrepreneur, penggunaan teknologi informasi, 
dan inovasi terhadap keunggulan bersaing menuju Asean Economic Community 2015 (Survei pada industri tenun sutra di Provinsi Selawesi Selatan dan Sulawesi Barat) dengan jenis penelitian adalah explanatory research. Jenis data yang digunakan yaitu primer dan sekunder dengan menyebarkan angket kepada 100 UKM Sutera, wawancara dan dokumentasi. Teknik pengambilan sampel mengacu kepada rumus yang dikemukakan oleh Taro Yamane sehingga diambil presisi 10\%. Respondennya yaitu pemilik usaha dari masing-masing UKM Sutera tersebut.

\section{Metode Analisis Data}

Metode analisis yang digunakan dalam penelitian ini analisis regresi berganda (Multiple Regression Analysis), dengan terlebih dahulu dilakukan pegujian validitas dengan menggunakan teknik korelasi Spearman, sedangkan untuk uji reliabilitas instrument dilakukan adalah dengan menggunakan Cronbach Alpha dan uji Asumsi Klasik yang dilakukan dengan bantuan program SPSS 20.

\section{Operasionalisasi Variabel}

Dalam mengukur variabel penelitian diatas, dilakukan operasionalisasi variabel yaitu penjabaran variabel-variabel tersebut kedalam indikator tertentu. Secara lengkap operasionalisasi variabel adalah sebagai berikut :

Tabel 1. Operasionalisasi Variabel

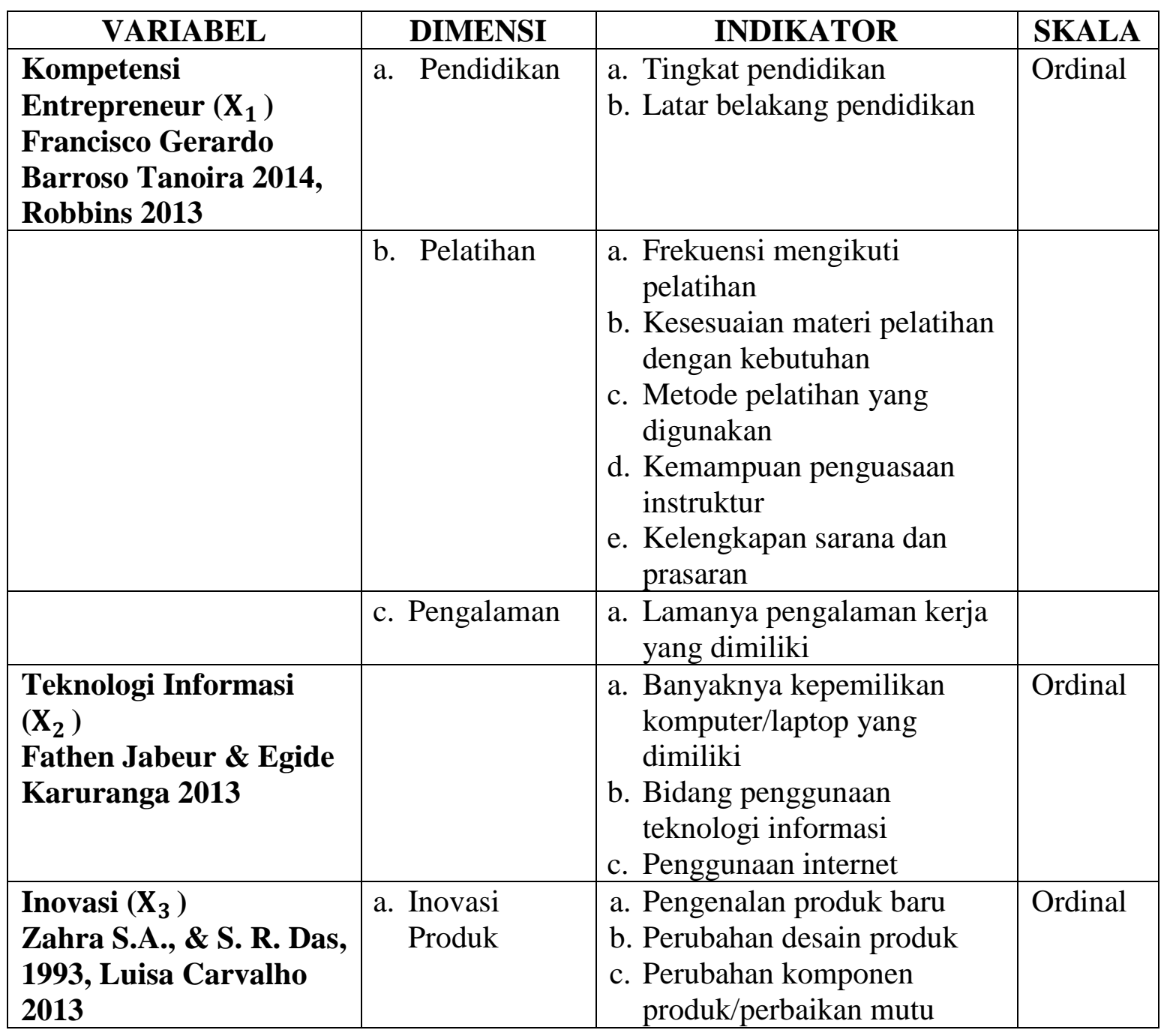




\begin{tabular}{|l|l|l|l|}
\hline & $\begin{array}{l}\text { b. Inovasi } \\
\text { Proses }\end{array}$ & $\begin{array}{l}\text { a. Adanya metode baru dari } \\
\text { proses produksi } \\
\text { b. Proses pengolahan limbah } \\
\text { untuk menjadi produk yang } \\
\text { memiliki nilai jual. } \\
\text { c. Adanya perubahan dalam } \\
\text { sistem pembayaran sesuai } \\
\text { kebutuhan pelanggan }\end{array}$ & \\
\hline $\begin{array}{l}\text { Keunggulan Bersaing } \\
\text { (Y) Michael Porter, }\end{array}$ & a. Lower cost & $\begin{array}{l}\text { a. Harga jual bersaing } \\
\text { b. Biaya produksi murah }\end{array}$ & Ordinal \\
\hline & d. Differentiatio & $\begin{array}{l}\text { a. Tidak mudah } \\
\text { ditiru/keunggulan }\end{array}$ & \\
bowen 2009 & $n$ & $\begin{array}{l}\text { bidak mudah diganti } \\
\text { c. Unik }\end{array}$ & \\
\hline
\end{tabular}

\section{Model Penelitian}

Pengujian atas hipotesis penelitian menggunakan model dengan persamaan sebagai berikut:

$$
Y=\alpha+\beta_{1} X_{1}+\beta_{2} X_{2}+\beta_{3} X_{3}+e
$$

Dimana :

$Y \quad=$ Keunggulan Bersaing Menuju Asean Economic Community 2015

$\alpha \quad=$ Konstanta

$X_{1} \quad=$ Kompetensi entrepreneur

$X_{2} \quad=$ Teknologi Informasi

$X_{3} \quad=$ Inovasi

$\beta_{1}, \beta_{2}, \beta_{3}=$ Koefisien arah regresi (koefisien pengaruh dari $X_{1}, X_{2}, X_{3}$ )

\section{HASIL \& ANALISIS}

\section{Gambaran Umum Lokasi Penelitian}

Sulawesi Selatan merupakan daerah penghasil sutera alam, khususnya di kabupaten Wajo. Kota ini merupakan daerah yang yang juga dikenal dengan nama 'Kota Sutera". Kegiatan pengembangan persuteraan di Kabupaten Wajo dapat ditemui disemua Kecamatan yang ada. Sampai saat ini, kabupaten Wajo masih menjadi daerah sentra pengembangan sutera alam di Sulsel, diikuti Soppeng, Sidrap dan Enrekang dan menjadi sentra industri Sutra terbesar pertama di Indonesia, untuk di provinsi Sulawesi Barat sentra produksi kain sutra terletak didaerah Polewali Mandar. Kementrian Kehutanan 2012 \& Direktorat Jenderal Industri Kecil dan Menengah.

Industri pertenunan sutera merupakan kegiatan yang banyak digeluti oleh pelaku persuteraan di Sulawesi Selatan dan Sulawesi Barat. Hal ini dilatar belakangi oleh produk kain sutera selain mempunyai nilai guna yang dipadukan dengan nilai estetika budaya setempat yang sangat tinggi juga memiliki nilai ekonomis. Perpaduan tersebut menghasilkan karakteristik tersendiri yang mencirikan produk kain sutera atau dalam bahasa setempat dikenal dengan sebutan "Lipa' Sabbe". Dalam perkembangannya pengrajin/pengusaha tenun sutera bukan saja menghasilkan kain sarung tetapi sudah mampu memproduksi kain lain seperti kain dengan tekstur bermotif maupun kain putih polos dan aneka warna dengan memadukan benang sutera dan bahan serat lainnya 
sehingga memberikan banyak pilihan bagi para peminat produk sutera. Hasil dari kain sutera juga dapat dijadikan pakaian adat Sulawesi seperti baju bodo, selendang, tas, aksesoris rumah tangga, aksesoris hotel, kantor dan lain sebagainya berdasarkan permintaan pasar/konsumen. Dalam proses produksinya pengrajin menggunakan beberapa alat tenun seperti alat tenun tradisional yaitu Alat Tenun Gedogan, Alat Tenun Bukan Mesin (ATBM) dan Mesin.

Selain diminati didaratan China dan Eropa Sutera Sulawesi Selatan dan Sulawesi Barat juga diminati konsumen dari Thailand, Singapura dan Malaysia. Melalui perwakilan kerajaan Negeri Treanggano Malaysia menyampaikan minatnya terhadap persuteraan di Sulawesi.Hal ini merupakan salah satu bukti bahwa kain asal Sulawesi ini juga bisa bersaing dipasar Asean maupun Internasional.

\section{Data Responden}

Adapun kuisioner yang dibagikan sebanyak 115 rangkap tetapi yang dikembalikan sebanyak 100 rangkap, dengan kata lain response rate yaitu sebesar $86,9 \%$. Berikut rekap data responden industri tenun sutera Sulawesi Selatan dan Sulawesi Barat :

Tabel 2. Responden UKM Sutera Berdasarkan Tingkat Pendidikan

\begin{tabular}{|c|l|c|}
\hline No & \multicolumn{1}{|c|}{ Uraian } & Keterangan \\
\hline \multicolumn{2}{|c|}{ Berdasarkan Tingkat Pendidikan : } \\
\hline 1 & Magister (S2) & 0 \\
\hline 2 & Strata 1 (S1) & 8 \\
\hline 3 & SLTA/SLTP & 24 \\
\hline 4 & SD & 68 \\
\hline Jumlah & $\mathbf{1 0 0}$ \\
\hline
\end{tabular}

Sumber: data diolah, 2014

Tabel 3. Responden UKM Sutera Berdasarkan Umur

\begin{tabular}{|c|c|c|}
\hline No & Uraian & Keterangan \\
\hline \multicolumn{2}{|c|}{ Berdasarkan Umur : } & \\
\hline 1 & $20-30$ Tahun & 30 \\
\hline 2 & $31-40$ Tahun & 50 \\
\hline 3 & $41-50$ Tahun & 12 \\
\hline 4 & $51-60$ Tahun & 8 \\
\hline Jumlah & $\mathbf{1 0 0}$ \\
\hline
\end{tabular}

Sumber: data diolah, 2014

\section{Pengujian Validitas, Reliabilitas, dan Uji Asumsi}

Uji validitas dilakukan untuk menilai instrument penelitian yang digunakan dapat mengukur apa yang ingin diukur dalam penelitian tersebut. Sedangkan Uji reliabilitas ditujukan untuk mengetahui stabilitas dan konsistensi didalam sebuah pengukuran. Hasil uji validitas Spearman dalam penelitian ini menunjukkan bahwa untuk variabel 
kompetensi entrepreneur, penggunaan teknologi informasi, inovasi dan keunggulan bersaing menuju Asean Economic Community 2015 semua butir pertanyaannya telah valid dengan nilai $>0,30$. Keempat instrumen penelitian untuk menilai keempat variabel dalam penelitian ini telah lolos uji reliabilitas Cronbach Alpha dengan hasil untuk variabel kompetensi entrepreneur, penggunaan teknologi informasi, inovasi dan keunggulan bersaing dengan nilai berturut-turut sebesar: $0.759 ; 0.734 ; 0.711 ; 0.723$ sehingga hasil pengukuran atas keempat variabel tersebut dapat dipercaya dengan titik kritis 0,70. Untuk uji asumsi klasik dalam penelitian diantaranya multikolinearitas, normalitas dan heterokedastisitas telah memenuhi untuk dilakukan pengujian berikutnya.

\section{Analisis Regresi Berganda}

Berikut ini disajikan tabel mengenai hasil analisis regresi yaitu :

\section{Tabel 4. Hasil Analisis Regresi Berganda}

\section{Coefficients $^{a}$}

\begin{tabular}{|c|c|c|c|c|c|c|c|c|}
\hline \multirow[t]{2}{*}{ Mode } & & \multicolumn{2}{|c|}{$\begin{array}{c}\text { Unstandardized } \\
\text { Coefficients }\end{array}$} & \multirow{2}{*}{$\begin{array}{c}\text { Standardized } \\
\text { Coefficients } \\
\text { Beta }\end{array}$} & \multirow[t]{2}{*}{$\mathrm{t}$} & \multirow[t]{2}{*}{ Sig. } & \multicolumn{2}{|c|}{ Collinearity Statistics } \\
\hline & & $\mathrm{B}$ & Std. Error & & & & Tolerance & VIF \\
\hline \multirow{4}{*}{1} & (Constant) & .420 & .439 & & .958 & .341 & & \\
\hline & Entrepreneur_competency & .110 & .027 & .238 & 4.117 & .000 & .147 & 6.806 \\
\hline & Information_technology & .186 & .055 & .124 & 3.402 & .001 & .373 & 2.679 \\
\hline & Innovation & .597 & .054 & .651 & 10.989 & .000 & .140 & 7.134 \\
\hline
\end{tabular}

a. Dependent Variable: Competitive_advantage

Dari output diatas diperoleh persamaan untuk regresi berganda sebagai berikut :

$$
Y=0,420+0,110 X_{1}+0,186 X_{2}+0,597 X_{3}+e
$$

Dari persamaan regresi berganda diperoleh nilai konstanta sebesar 0,420. Artinya bahwa jika keunggulan bersaing tidak dipengaruhi oleh variabel independen kompetensi entrepreneur $\left(\mathrm{X}_{1}\right)$, penggunaan teknologi informasi $\left(\mathrm{X}_{2}\right)$, inovasi $\left(\mathrm{X}_{3}\right)$ dalam hal ini bernilai 0 , maka besarnya keunggulan bersaing pada Industri Sutra Sulawesi selatan dan Sulawesi Barat adalah sebesar 0,420.

Dilihat dari tanda koefisien regresi variabel independen menunjukkan arah hubungannya dengan variabel dependen. Koefisien regresi variabel Kompetensi entrepreneur $\left(\mathrm{X}_{1}\right)$ bertanda positif sebesar 0,110 yang menunjukkan adanya hubungan yang positif dan searah antara variabel kompetensi entrepreneur dengan keunggulan bersaing menuju Asean Economic Community 2015 (Survei pada industri tenun sutra di Provinsi Selawesi Selatan dan Sulawesi Barat) hal ini mengandung arti bahwa untuk setiap peningkatan variabel kompetensi entrepreneur maka akan cenderung menyebabkan meningkatnya pula keunggulan bersaing.

Koefisien regresi variabel penggunaan teknologi informasi $\left(\mathrm{X}_{2}\right)$ bertanda positif sebesar 0,186 yang menunjukkan adanya hubungan yang positif dan searah antara variabel penggunaan teknologi informasi dengan keunggulan bersaing menuju Asean Economic Community 2015 (Survei pada industri tenun sutra di Provinsi Selawesi Selatan dan Sulawesi Barat), hal ini mengandung arti bahwa untuk setiap peningkatan variabel penggunaan teknologi informasi maka akan menyebabkan meningkatnya pula keunggulan bersaing. 
Koefisien regresi variabel Inovasi $\left(\mathrm{X}_{3}\right)$ bertanda positif sebesar 0,597 yang menunjukkan adanya hubungan yang positif dan searah antara variabel Inovasi dengan keunggulan bersaing menuju Asean Economic Community 2015 (Survei pada industri tenun sutra di Provinsi Selawesi Selatan dan Sulawesi Barat), hal ini mengandung arti bahwa untuk setiap peningkatan variabel Inovasi maka akan menyebabkan meningkatnya pula keunggulan bersaing.

\section{Pengujian Hipotesis Secara Simultan (Uji F)}

Hipotesis yang menyatakan bahwa :

$\mathrm{H}_{0}: \beta_{\mathrm{i}} \leq 0$ Kompetensi Entrepreneur, Penggunaan Teknologi Informasi, dan Inovasi tidak berpengaruh positif terhadap Keunggulan Bersaing Menuju Asean Economic Community 2015 secara simultan.

$\mathrm{H}_{\mathrm{a}}: \beta_{\mathrm{i}}>0$ Kompetensi Entrepreneur, Penggunaan Teknologi Informasi, dan Inovasi berpengaruh positif terhadap Keunggulan Bersaing Menuju Asean Economic Community 2015 secara simultan.

Proses pengujian dilakukan dengan melihat pada kolom signifikansi dan nilai $\mathrm{F}$ di ANOVA dengan mengunakan tingkat signifikansi $(\alpha)$ sebesar $5 \%$ atau 0.05 . Dasar pengambilan keputusannya yaitu :

Jika signifikansi $<0,05$, maka $\mathrm{H}_{0}$ ditolak (rejected),

Jika signifikansi $>0,05$, maka $\mathrm{H}_{0}$ diterima (not rejected)

Berikut ini disajikan tabel mengenai hasil uji F (Simultan) yaitu :

Tabel 5. Hasil Uji F

\begin{tabular}{|rl|r|r|r|r|r|}
\hline \multicolumn{1}{|c|}{ Model $^{2}$} & Sum of Squares & Df & Mean Square & F & Sig. \\
\hline \multirow{2}{*}{1} & Regression & 317.939 & 3 & 105.980 & 645.112 & $.000^{\mathrm{b}}$ \\
& Residual & 15.771 & 96 & .164 & & \\
& Total & 333.710 & 99 & & & \\
\hline
\end{tabular}

a. Dependent Variable: Competitive_advantage

b. Predictors: (Constant), Innovation, Information_technology, Entrepreneur_competency

Kompetensi Entrepreneur, Penggunaan Teknologi Informasi, dan Inovasi berpengaruh positif terhadap Keunggulan Bersaing Menuju Asean Economic Community 2015 secara simultan telah dibuktikan melalui pengujian hipotesis, atau dengan kata lain bahwa $\mathrm{H}_{0}$ ditolak (rejected). Hal ini terlihat dari output pada tabel 5 dengan sig $0,000<$ dari $\alpha 0,05$.

\section{Pengujian Hipotesis Secara Parsial (Uji t)}

Dari hasil pengujian masing-masing variabel Kompetensi Entrepreneur, Penggunaan Teknologi Informasi, dan Inovasi terhadap Keunggulan Bersaing Menuju Asean Economic Community 2015 menunjukkan bahwa ketiga variabel tersebut terbukti memiliki pengaruh positif secara parsial hal ini terlihat dari nilai sig berturut-turut 0,000 ; 0,001 ; dan $0,000<$ dari $\alpha 0,05$. 


\section{Koefisien Determinasi}

Tabel 6. Hasil Koefisien Determinasi

\begin{tabular}{|l|r|r|r|c|}
\hline Model & $\mathrm{R}$ & $\mathrm{R}$ Square & $\begin{array}{c}\text { Adjusted R } \\
\text { Square }\end{array}$ & $\begin{array}{c}\text { Std. Error of the } \\
\text { Estimate }\end{array}$ \\
\hline 1 & $.976^{\mathrm{a}}$ & .953 & .951 & .40532 \\
\hline
\end{tabular}

a. Predictors: (Constant), Innovation, Information_technology,

Entrepreneur_competency

b. Dependent Variable: Competitive_advantage

Berdasarkan tampilan output model summary pada tabel 6, besarnya adjusted $R$ Square adalah 0,951. Hal ini menunjukkan bahwa $95 \%$ variasi Keunggulan Bersaing pada Industri sutra di Sulawesi selatan dan Sulawesi barat dapat dijelaskan oleh variasi dari ketiga variabel independen yaitu Kompetensi Entrepreneur, Penggunaan Teknologi Informasi, dan Inovasi, sedangkan sisanya $5 \%$ dijelaskan oleh faktor lain di luar model regresi yang digunakan.

\section{Pembahasan}

\section{Pengaruh Kompetensi Entrepreneur terhadap Keunggulan Bersaing}

Dilihat dari tingkat pendidikan entrepreneur menunjukan bahwa tingkat pendidikannya masih rendah hal ini terlihat dari sebagian besar responden atau $68 \%$ berpendidikan SD dan tidak tamat SD. Serta frekuensi mengikuti pelatihan yang masih tergolong jarang. Sedangkan untuk dimensi pengalaman sebagian besar telah memiliki pengalaman beberapa tahun dalam industri sutra. Industri sutra ini secara umum memang ditekuni secara turun temurun oleh masyarakat di Sulawesi Selatan dan Sulawesi Barat dan pada umumnya mereka mendapatkan pengetahuan dan keterampilan mengenai industri tenun sutera dari orang tua atau keluarga lainnya. Apabila kompetensi entrepreneur ini semakin ditingkatkan maka akan memberikan pengaruh yang positif terhadap keunggulan bersaing perusahaan. Usaha yang ditangani oleh pihak yang berkompeten akan lebih baik dari pada ditangani oleh yang tidak berkompeten.

Hasil penelitian ini sejalan dengan penelitian yang dilakukan oleh Francisco Gerardo Barroso Tanoira, (2014) di Mexico bahwa ada pengaruh yang kuat dari entrepreneur Competency yang akan meningkatkan produktivitas dan keunggulan perusahaan, Theresa Lau, (2008); Noor Hazlina Ahmad (2011), hal ini didukung oleh Eka Handriani (2011) bahwa ada pengaruh yang positif dari variabel entrepeurskill terhadap daya saing UKM di Kabupaten Semarang,

\section{Pengaruh Penggunaan Teknologi Informasi terhadap Keunggulan Bersaing}

UKM yang memiliki komputer atau sudah menggunakan peran teknologi dalam membantu sistem usahanya, berarti mereka telah memahami pentingnya peran teknologi informasi untuk meningkatkan produktivitas industri sutra yang nantinya akan bermuara pada pembentukan industri sutra yang berdaya saing. Bidang penggunaan teknologi informasi cukup bervariasi. Pada umumnya industri sutera telah memiliki teknologi informasi berupa komputer untuk administrasi. Penggunaan teknologi informasi 
pemasaran masih kurang digunakan, pada umumnya pemasaran mengandalkan pemasaran melalui pameran produk seni budaya baik didalam negeri maupun diluar negeri, membuka toko atau gerai dan dipasarkan didaerah lain, sedangkan penggunaannya untuk proses produksi masih terbilang rendah dibanding bidang lainnya. Dalam hal penggunaan teknologi internet juga masih terbilang sangat jarang terlebih lagi usaha ini berada didaerah kabupaten yang masih belum terbiasa dengan penggunaan internet untuk tujuan pemasaran. Hal ini juga merupakan implikasi dari keterbatasan sumber daya manusia yang terampil menggunakan teknologi informasi.

Pada dasarnya untuk tujuan pengembangan promosi rnelalui internet dapat dilakukan melalui beberapa cara yaitu:

a. Website, industri sutera bisa membuat website bagi jasa atau produk yang akan dijual dan masukkan website tersebut ke dalam search engine.

b. Mailing list, industri sutera bisa mengirimkan promosi produk dalam bentuk e-mail ke mailing list yang relevan dengan yang ditawarkan.

c. Chat, industri sutera bisa menggunakan sarana chatting untuk menawarkan produk atau jasa diantaranya bisa melalui facebook, twitter, yahoo, bahkan melalui blackberry messanger dll.

Hasil penelitian ini sejalan dengan penelitian yang dilakukan oleh Jabeur, Fathen \& Egide Karuranga (2013) di Canada, Arief Rahmana (2009), Sri Eka Pebruati (2008), Fatmariani (2011) Menyatakan bahwa rendahnya tingkat adopsi teknologi dalam kelompok UKM yang berada diderah pedesaan dibandingkan dengan perusahaan yang berada didaerah metropolitan yang cenderung lebih cepat dan volume yang lebih tinggi dalam mengadopsi teknologi informasi (e-business). Adopsi teknologi informasi dapt memberikan pengaruh positif terhadap keunggulan bersaing pada UKM.

\section{Pengaruh Inovasi terhadap Keunggulan Bersaing}

Penerapa inovasi produk pada industri sutera di Sulawesi Selatan dan Sulawesi Barat terbilang cukup sering dilakukan. Dari hasil kuesioner menunjukkan bahwa industri sutera melakukan inovasi produk seperti melakukan pengenalan produk baru, perubahan desain produk atau motif kain sutera, perubahan komponen produk/perbaikan mutu. Beberapa motif atau sure' tradisional yang disediakan adalah : motif "Balo Tettong" (bergaris atau tegak), motif "Makkalu" (melingkar), motif "Mallobang" (berkotak kosong), motif "Balo Renni" (berkotak kecil). Selain itu ada juga diproduksi dengan mengkombinasikan atau menyisipkan "Wennang Sau" (lusi) timbul, motif "Bali Are". Motif di Sulawesi barat diantaranya : sure' salaka (motif perak), sure' pangulu (motif penghulu), sure padhadha, sure jassa, sure' batu dalima, sure gattung layar, sure puang limboro. Inovasi tidak hanya dilakukan terhadap produk tetapi juga bisa mencakup inovasi proses seperti : inovasi dalam proses produksi, inovasi dalam proses pembayaran. Perusahaan yang mampu mendesain produknya sesuai keinginan pelanggan akan mampu bertahan ditengah persaingan karena produknya tetap diminati oleh pelanggan. Produk inovasi pada dasarnya adalah untuk memenuhi permintaan pasar sehingga produk inovasi merupakan salah satu yang dapat digunakan sebagai keunggulan bersaing bagi perusahaan.

Hasil penelitian ini sejalan dengan penelitian yang dilakukan oleh Evelyn GarciaZamora (2013) di Spanyol dengan inovasi produk akan memberikan kinerja terbaik bagi perusahaan. Jos M. Monteiro Barata (2012); Yongyoon Suh \& Moon Soo Kim (2014); Mohammad Soleh (2008); bahwa strategi inovasi berpengaruh positif terhadap kinerja UKM di Kota Semarang sehingga menciptakan keunggulan bersaing, 
Variabel yang paling dominan yang menyebabkan perubahan dari keunggulan bersaing pada Industri Sutra di Sulawesi Selatan dan Sulawesi Barat adalah variabel Inovasi dengan koefisien $=0,597$. Hal ini mengindikasikan bahwa seharusnya variabel Inovasi sebagai variabel yang lebih dominan yang semestinya diprioritaskan untuk ditingkatkan Karena pengaruhnya yang paling kuat dalam rangka perbaikan atau peningkatan keunggulan bersaing dibanding dua variabel independen lainnya .

\section{PENUTUP}

Dari hasil penelitian dapat disimpulkan bahwa terdapat pengaruh positif variabel kompetensi entrepreneur, penggunaan teknologi informasi, dan inovasi terhadap keunggulan bersaing menuju Asean Economic Community 2015 (Survei pada industri tenun sutra di Provinsi Selawesi Selatan dan Sulawesi Barat).

Mengacu pada temuan penelitian dan kesimpulan maka dikemukakan saran-saran berikut:

1. Pelaku industri sutra perlu lebih memperhatikan hal-hal yang belum dikelola secara optimal seperti promosi dan lebih memanfaatkan peran teknologi informasi dalam pengelolaan usaha baik untuk tujuan administrasi, produksi, maupun pemasaran. Keikutsertaan usaha kecil dalam pameran produk perlu ditingkatkan dan kerjasama dengan institusi penelitian dan perguruan tinggi perlu terus digalakkan.

2. Strategi dalam mengelola lingkungan eksternal melalui entrepreneurial skill perlu ditingkatkan untuk meningkatkan kinerja dan keunggulan bersaing.

3. Dibutuhkan peran Pemerintah yang lebih besar untuk mendukung pengembangan industri tenun sutera seperti memberikan bantuan permodalan yang lebih mudah kepada pelaku industri.

\section{DAFTAR PUSTAKA}

Bigliardi, Barbara. 2013. The effect of innovation on : a research study involving SMEs. Innovation: Management, Policy, \& Practice. 15.2 June: p245.

Boyles, Trish. 2012. 21st Century knowledge, skills, and abilities and entrepreneurial competencies: a model for undergraduate entrepreneurship education. Journal of Entrepreneurship Education. 15 Annual: p41

Carvalho, Luisa, Teresa Costa \& Jorge Caiado. 2013. Determinants of innovation in a small open economy: a multidimensional perspective. Journal of Business Economics and Management. 14.3 June: p583

Cravens, David, Nigel Piercy. 2012. Strategic Marketing. Tenth Edition. McGraw-Hill

Damanpour, F., \& Evan, W. M. 1984. Organizational innovation and performance: The problem of organizational lag. Administrative Science Quarterly, 29, 392-409.

Droge, Cornelia \& Shownee Vickrey. 1994. "Source and Outcomes of Competitive Advantage: An Explanory Study in The Furniture Industry”. Decision Sciences. p.669-689. 
Peningkatan Daya Saing dalam Menghadapi Asean Economic Community (AEC) 2015

Himpunan Mahasiswa Pascasarjana

Fakultas Ekonomi \& Bisnis - Universitas Padjadjaran

ISBN : 978-602-9238-60-0

Eka Handriani, 2011. Pengaruh Faktor Internal Eksternal, Entrepreneurial Skill, Strategi dan Kinerja Terhadap Daya Saing Ukm Di Kabupaten Semarang. Jurnal Dinamika Sosial Ekonomi Volume 7 Nomor 1

Eka, Sri Pebruati Tj, Siti Ragil Handayani, Zahroh Z.A.2008. Pengaruh aplikasi teknologi informasi dalam peningkatan Daya saing perusahaan (Studi Pada Ukm Kota Malang ) Jurnal Profit Vol 7 No. 1

Fatmariani. 2011. Pengaruh Adopsi Teknologi Informasi Open Source e-commerce terhadap Kinerja UKM dengan Faktor-Faktor Technology Acceptance Model (Tam) Sebagai Moderating Variable. Jurnal teknologi dan informatika (teknomatika) vol. 1 no. 1

Gerardo, Francisco Barroso Tanoira \& Raul Alberto Santos Valencia. 2014. Knowledge management, entrepreneurial competencies and organizational development in micro and small enterprises in rural regions in the state of Yucatan, Mexico. European Scientific Journal. 10 Jan. 1 p177

Hansen, Maryanne M. Mowen. 2009. Cost Management Accounting and Control. sixth Edition. Thomson South-Western

Hazlina, Noor Ahmad, Liz Kummerow \& Carlene Wilson.2011. A cross-cultural insight into the competency-mix of SME entrepreneurs in Australia and Malaysia. International Journal of Business and Management Science. 4.1 July : p33

Husband, S. and Purnendu, M. 1999, "A Conceptual Model for Quality Inetgrated Management in Small and Medium Size Enterprise", International Journal of Quality \& Reliability Management, Vol. 16 No.7, pp. 699

Hunger, David Whelen, Thomas. 2013. Essentials of Strategic Management. USA: Pearson Education Inc

Jabeur, Fathen \& Egide Karuranga. 2013. Timeline of Initial Perceptions and Adoption of e-Business Among Quebec Forestry Sector SMEs. Communications of the IIMA. 13.3 (Aug. 2013): p1.

Jong, J. P. J., \& Vermeulen, P. A. M. 2006. Determinants of product innovation in small firms: A comparison across industries. International Small Business Journal, 24(6), 587-609.

Lau, Theresa, Thomas W.Y. Man \& Ed Snape. 2008. Entrepreneurial competencies and the performance of small and medium enterprises: an investigation through a framework of competitiveness. Journal of Small Business and Entrepreneurship. 21.3 Summer 2008: p257

Monteiro, Barata Jos M \& Rita Gomes Batista. 2012. Design and competitiveness in a Portuguese SME in the footwear industry: a case study. Source. International Journal of Business Competition and Growth. Vol 2.3 (July 12, 2012) : p256 
Porter, M. 1980. Competitive Strategy Techniques For Analyzing Industries And Competitors. Free Press, New York. 1-336 pp.

Rahmana, Arief. 2009. Peranan Teknologi Informasi Dalam Peningkatan Daya Saing Usaha Kecil Menengah. Paper Seminar Nasional Aplikasi Teknologi lnformasi 2009 (SNA TI 2009)

Robbins, S. \& Judge, T. 2013. Organizational behavior (15a. ed.). U. S. A.: Prentice Hall.

Riduwan, Engkos Ahmad Kuncoro. 2012. Cara Menggunakan Path Analisis. Bandung:Alfabeta

Sadapotto, Andi. 2012. Proses Kebijakan Persuteraan Alam di Sulawesi Selatan. Jurnal Perennial Vol. 8 No. 1: 1-5 Lab. Pemanfaatan dan Pengolahan Hasil Hutan, Fakultas Kehutanan Universitas Hasanuddin

Santoso, Singgih. 2012. Panduan Lengkap SPSS. Jakarta : Elex Media Komputindo 2010. Statistik Non Parametrik, Konsep dan Aplikasi dengan SPSS. Jakarta : Elex Media Komputindo

Sekaran, Uma. 2010. Research Methods For Business. $5^{\text {th }}$ Edition. United Kingdom : John Wiley \& Sons

Suh, Yongyoon \& Moon Soo Kim. 2014. Internationally leading SMEs vs. internationalized SMEs: Evidence of success factors from South Korea. International Business Review. 23.1 (Feb. 2014): p115.

Tavosi, Roghaye Simkami. 2013. The role of small and medium entrepreneurial enterprises in development: a management perspective in Iran. Advances in Environmental Biology : p1473.

Weiss, Barbara \& Dianne H.B. Welsh 2013. Entrepreneurship and small business in Eastern Europe: overcoming challenges, sustaining growth. International Journal of Globalisation and Small Business. 5.3 June 23: p148

Zahra, S.A., dan S. R. Das. 1993, Innovation Strategy and Financial Performance in manufacturing companies: An empirical Study. Production and Operations Management 2 (I) (Winter) : 15-37 